\title{
Effect of Lubrication and Friction Coefficient on Temperature Distribution for Combined Backward Forward Extrusion Process For Alloy Steel
}

\author{
Ban Alamer ${ }^{1 *}$ Çetin Karataş ${ }^{2,}$, Faruk Mert ${ }^{3}$ Haitham Aljawad ${ }^{4}$ \\ ${ }^{1}$ Department of Mechanical Engineering, THK University, Ankara, 06105, Turkey \\ ${ }^{2}$ Department of Manufacturing Engineering, Gazi University, Ankara, o6500, Turkey \\ ${ }^{3}$ Department of Manufacturing Engineering, Gazi University, Ankara, 06500, Turkey \\ ${ }^{4}$ Department of Mechanical Engineering, THK University, Ankara, 06105, Turkey
}

\begin{abstract}
During extrusion process, the effects of friction between die and workpiece are important and it is one of the most serious problems in metal forming. Friction factor has different effects depending on the size of workpiece. In this study the effect of friction factor and lubrication effects on temperature distribution, power, and load for combined backward forward extrusion process was demonstrated . A numerical analysis based on finite element method by using Q form program was used to study the effect of friction factor through two type of condition, first for lubrication three values for friction factor were used $(0.1,0.2,0.3)$.The second condition was un lubrication, the friction factors values were $(0.25,0.5,0.75)$. The material of specimen was steel C45.The parts to be manufactured was wrench socket and the lubrication was done by using water and graphite .The results showed that for lubricated and un lubricated conditions, the temperatures power and load were increased when the friction factor increased.
\end{abstract}

Keywords: Lubrication, Friction factor, combined extrusion, temperature distribution .

\section{Introduction}

Extrusion process needs elevated velocity and pressure which they lead to high friction during the process and cause the wear to the die in contact area between the workpiece and die parts. The high value of friction depend on the material of specimen, velocity and pressure in contact surfaces which they exposed the process to high stress amount then increase fatigue and wear influences . M $\mathrm{O}$ mutlu et al. studied the methods to raise wear resistance and die life . They used various surface treatment to explain the influences of friction condition on the process and how improve the quality of the products and reduce the force of friction on contact areas and decrease the cost of production by increase die life. This has been done by control the important properties such as hardness, toughness and wear resistance at high temperatures which ensure continuance for good grade of parts production [1]. A Farhoumand et al. used finite element techniques to demonstrate the effect of process condition for example friction effects during combined extrusion process by using ABAQUS method. In combined extrusion process the workpiece forced together in both forward and backward direction through the die, this process involve high amount of friction especially in cold working and with unlubricated [2]. For thin walled rectangular of aluminum specimen through indirect extrusion process the effect of lubrication was studied by using high aspect ratio .Solid lubricants were used by finite volume method to show friction effects with different shear friction factors . An important influence of lubrication on the product were shown, high friction factor raise the extrusion height of big side of the container and reduce extrusion height .Load of forming effected by lubrication and it is increased with the friction factor linearly. [3] In order to produce smooth surface products , microgroove arrays was used with cold forming for aluminum. Lubricants with vegetable 
oils give larger adhesion between aluminum work piece and the tool than the mineral oils. Roughness of the workpiece increase after the area of micro groove arrays when using soybean oil as lubrication, but it was still smooth near exit zone with other type of lubricants . [4] In combined extrusion tool geometry, friction and lubrication have different influences with material flow ,FEM was used to estimate the values which was suitable also for industrial application. The simulation solution determined the extrusion process properties and then designed the tools of die then send to production [5]. Another method for reduce friction by using lubrication was the servo press, an analysis of friction was done in experimental and numerical solution for combined extrusion to keep lubrication. Extrusion of deep holes was used with punch and servo press provide with internal channel for supplying liquid lubrication by using pulsed and stepwise method. A suitable liquid lubrication will apply on deformation region during punch withdraw .[6] Finite element method of deform software was used to estimate the stresses and strains and load in combined extrusion process for aluminum rod by used two types of punch shapes, speed and friction factors [7]. For Aluminum extrusion, vegetable oil was lubricants to compare with other lubricants, it is seen that this type of lubricants was suitable because of its heat reduction ability. Increase of temperature during extrusion lead to surface crack which was the main defect during metal forming. The study found that this type of lubricants give good surface quality by effect of good cooling and reducing temperature during proceed of process [8]. During studying the effect of lubrication on load for direct extrusion , it is shown that the friction increase because of the relative motion between workpiece and tool surface and lead to increase the force required an process defects ,a theoretical and experimental study was done by test the effect of lubrication, die angle on extrusion force . It was found that the flow of material was uniform and steady and the force reduce when using lubrication [9].A study in cold forging by double backward extrusion process demonstrate the effect of lubrication and friction by using 2D FEM with many reduction ratios and workpiece shapes.The condition of experimental work was near to the industrial production, large deformation and pressure interface was found after the process [10]. An extrusion process for composite material of $\mathrm{Al} / \mathrm{Si}$ was studied by using 3 reduction ratios to estimate the effect of friction factor on the process.The load and flow stress were reduced when heating the material to $300 \mathrm{C}$. The friction factor increase for high reduction area and surface roughness was better than stir casting [11]. In combined backward forward extrusion process for hollow parts of brass at micro scale, friction factor was estimated by using many ratios of cup heights to the rod lengths of workpiece .Many types of lubrications were used, to show that the dry process gives high amount of friction, and the friction factor increase with grain size increase. 


\section{Materials and method}

A finite element method of 3D Q Form software was used to analyze the combined backward forward extrusion process for steel $\mathrm{C} 45$ which has ( $0.42 \mathrm{C}, 0.40 \mathrm{Cr}, 0.50 \mathrm{MN}, 0.40 \mathrm{Ni}, 0.40 \mathrm{Si}$ ). The die material is H13 HRC50 .The load of press is $5 \mathrm{MN}$ with hydraulic press machine, graphite with water was used as lubricants . The process is cold extrusion process with environment temperature $20^{\circ}$ .two types of friction factor are used $(0.25,0.5,0.75)$ for un lubrication condition and $(0.1,0.2,0.3)$ for lubrication condition .

\section{Simulation results}

\section{1 . Lubrication condition}

Table 1. The results of power, load and temperature for lubrication condition

\begin{tabular}{cccc}
\hline $\begin{array}{c}\text { Friction } \\
\text { factor }\end{array}$ & $\begin{array}{c}\text { Temperature } \\
\left(\mathrm{C}^{\circ}\right)\end{array}$ & $\begin{array}{c}\text { Power } \\
(\mathrm{W})\end{array}$ & $\begin{array}{c}\text { Load } \\
\mathrm{MN}\end{array}$ \\
\hline 0.1 & 225 & 2452 & 0.703 \\
0.2 & 226 & 2969 & 0.871 \\
0.3 & 238 & 3559 & 1.052 \\
\hline
\end{tabular}

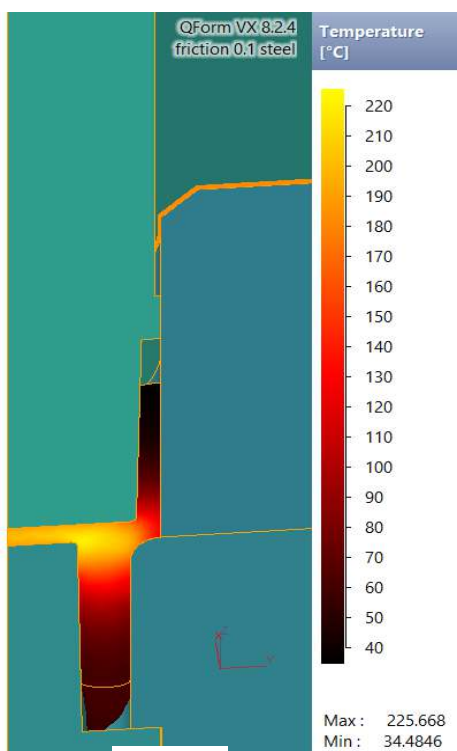

(a)

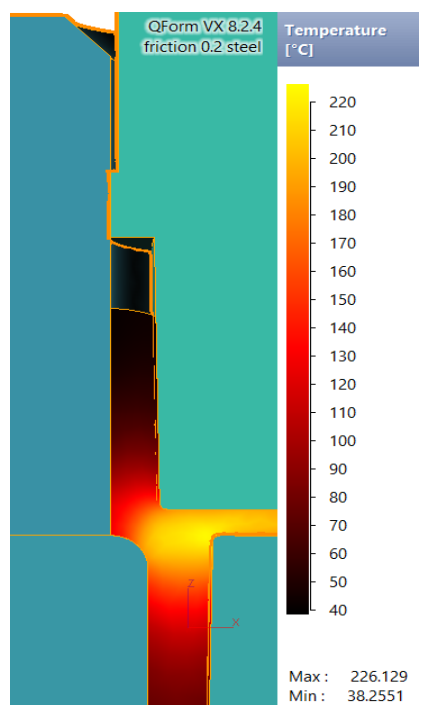

(b)

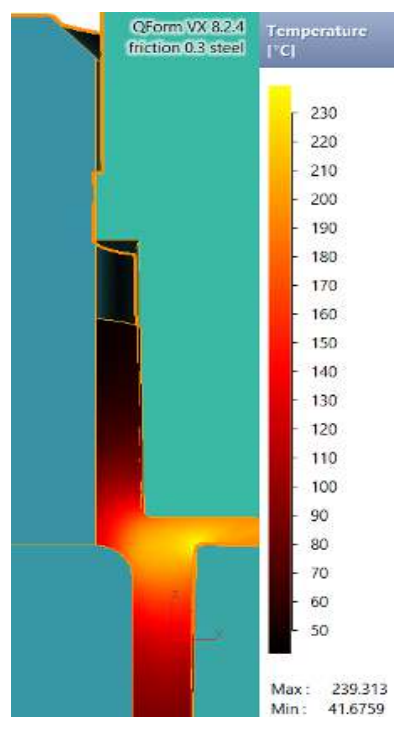

(c)

Figure 1. Temperature distribution for combined extrusion for lubrication condition for friction factor
(a) 0.1
(b) 0.2
(c) 0.3

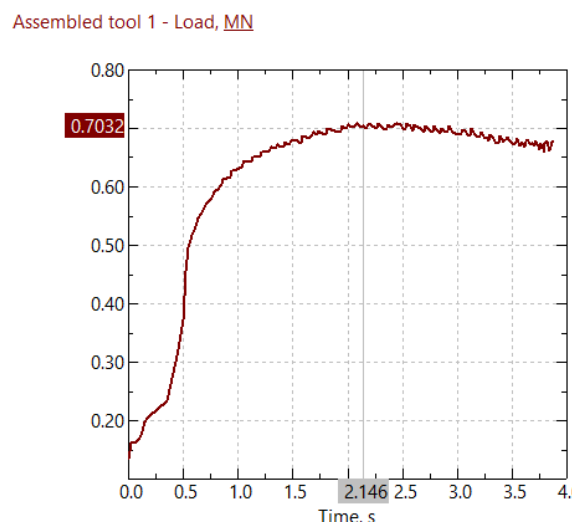

(a)
Assembled tool 1 - Load, MN

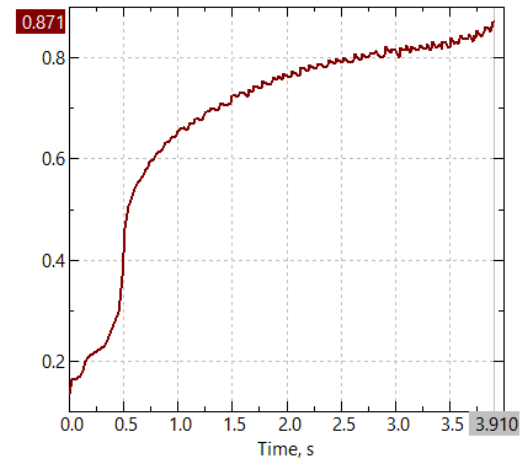

(b)

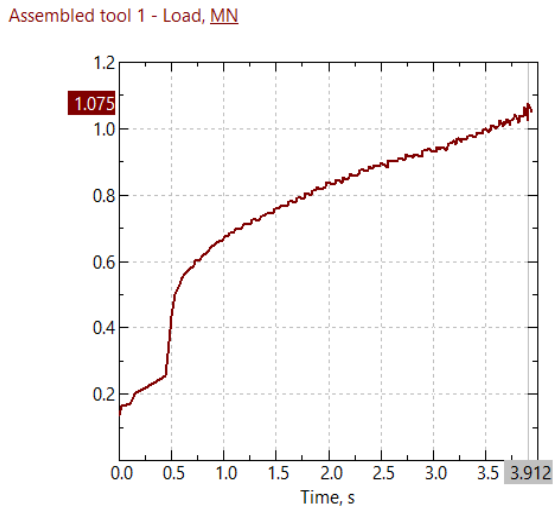

(c)

Figure 2. The load for combined extrusion for lubrication condition at friction factor
(a) 0.1
(b) 0.2
(c) 0.3 
Assembled tool 1 - Power, W

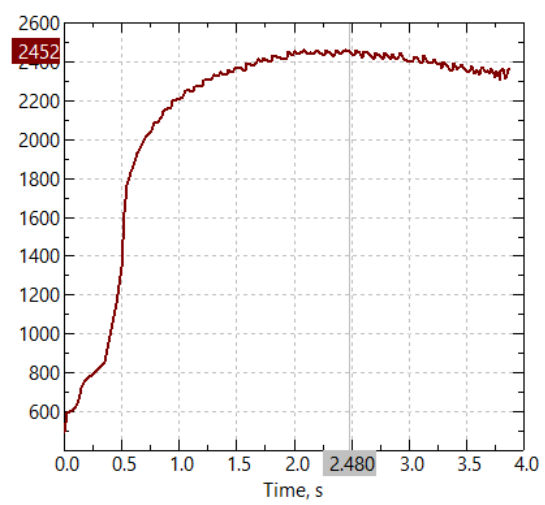

(a)

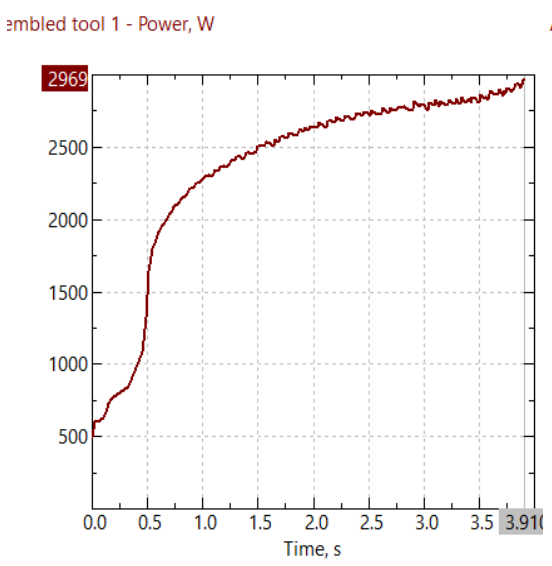

(b)

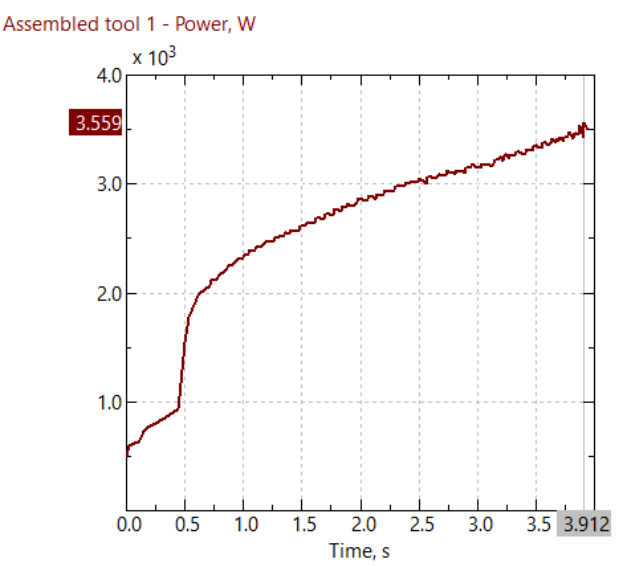

(c)

Figure 3. The power for combined extrusion for lubrication condition at friction factor
(a) 0.1
(b) 0.2
(c) 0.3

\subsection{Un lubrication condition}

Table 2. The results of power, load and temperature for un lubrication condition

\begin{tabular}{cccc}
\hline $\begin{array}{c}\text { Friction } \\
\text { factor }\end{array}$ & $\begin{array}{c}\text { Temperature } \\
\left(\mathrm{C}^{\circ}\right)\end{array}$ & $\begin{array}{c}\text { Power } \\
(\mathrm{W})\end{array}$ & $\begin{array}{c}\text { Load } \\
\mathrm{MN}\end{array}$ \\
\hline 0.25 & 240 & 3241 & 0.962 \\
0.5 & 274 & 4714 & 1.503 \\
0.75 & 344 & 5737 & 1.963 \\
\hline
\end{tabular}

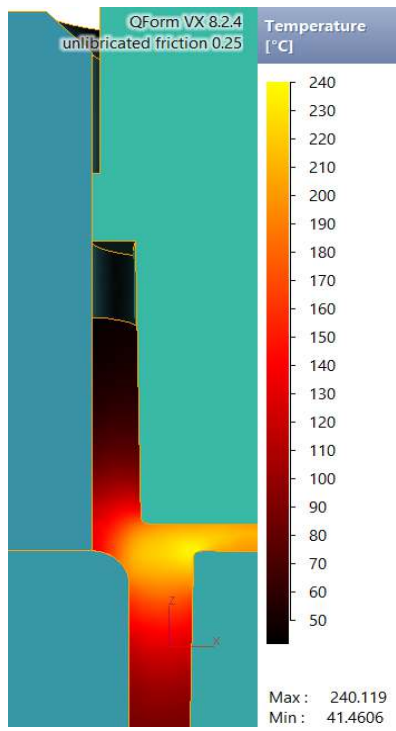

(a

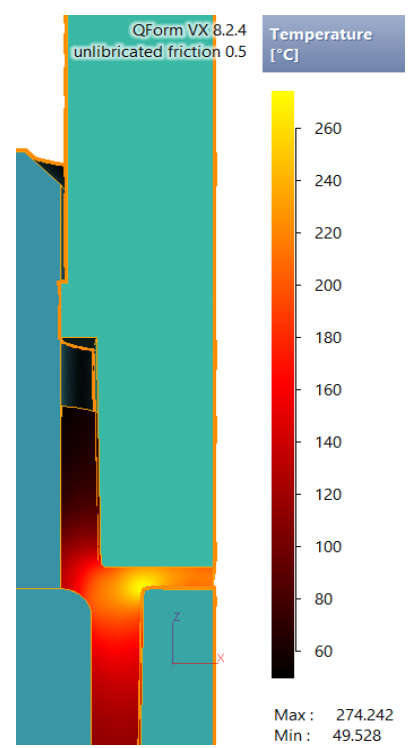

(b

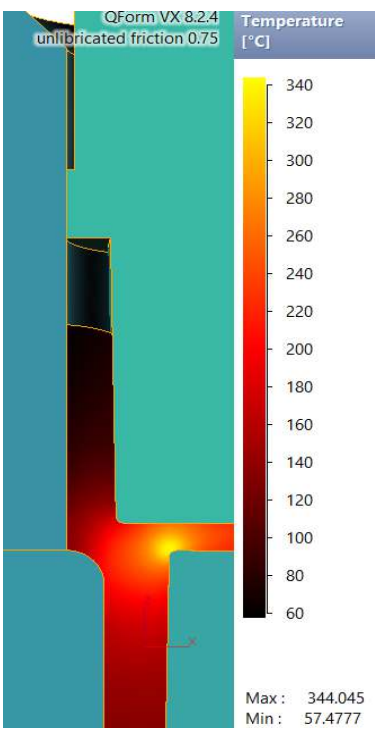

(c

Figure 4. Temperature distribution for combined extrusion for un lubrication condition at friction factor
(b) 0.1
(b) 0.2
(c) 0.3 
Assembled tool 1 - Load, $\underline{\mathrm{MN}}$

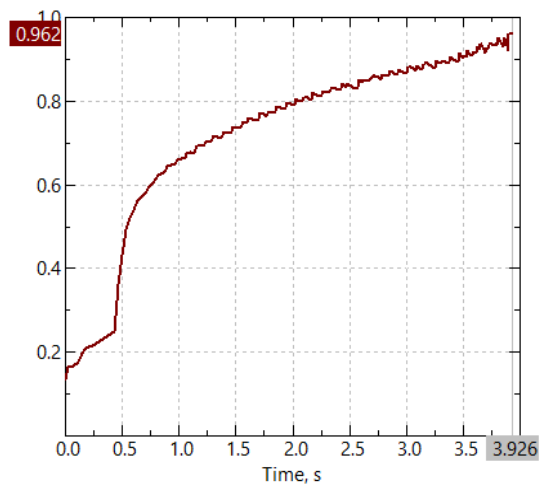

(a)

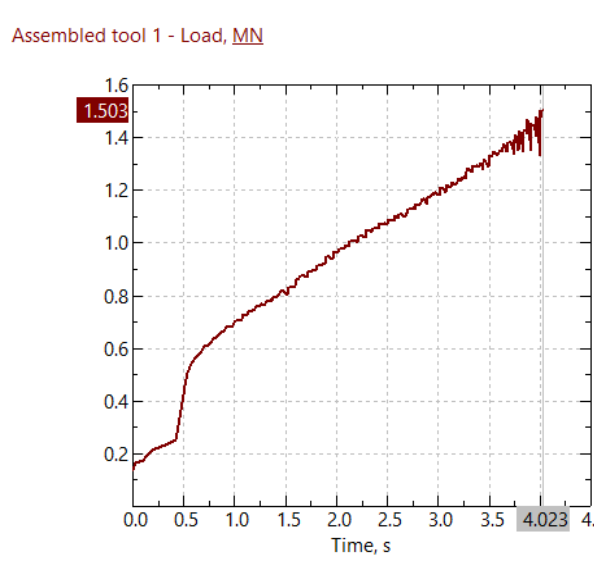

(b)

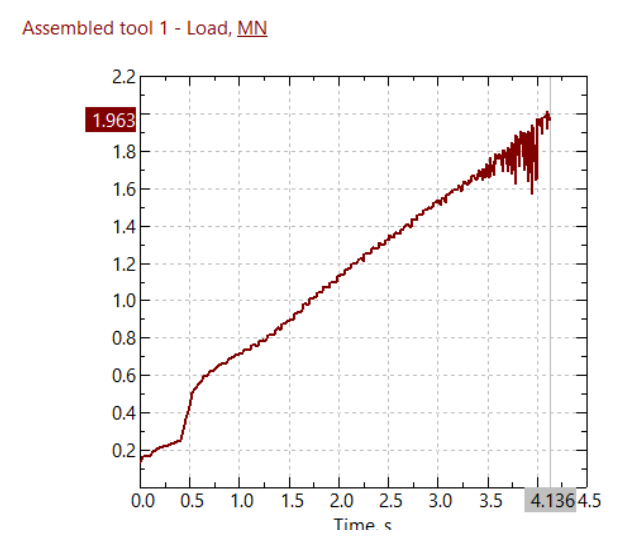

(c)

Figure 5. The Load for combined extrusion for un lubrication condition at friction factor
(a) 0.1
(b) 0.2
(c) 0.3

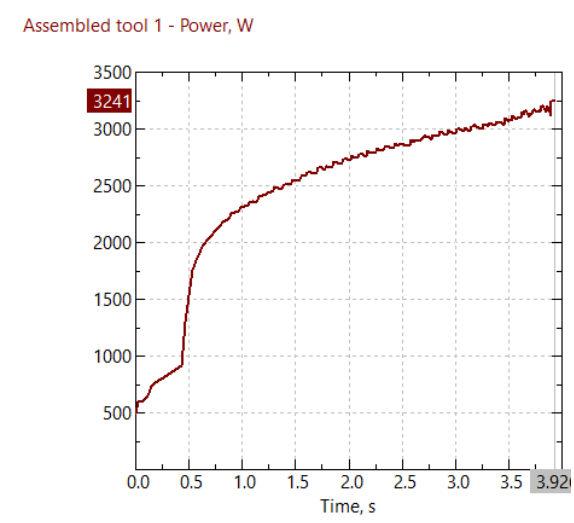

(a)

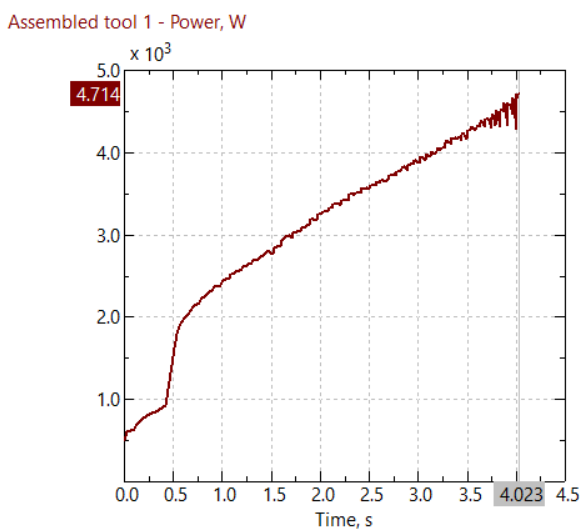

(b)

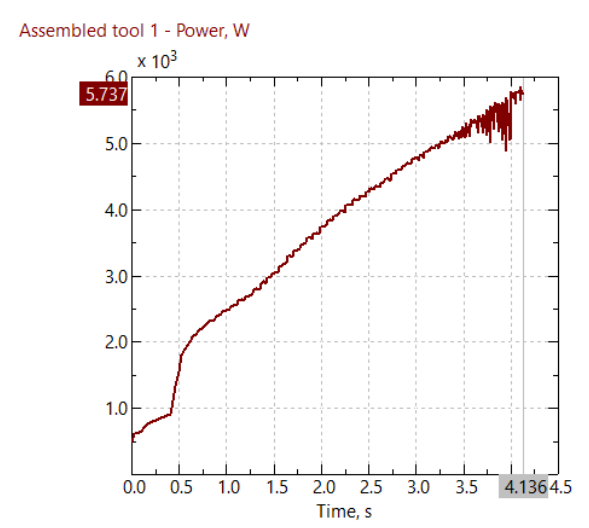

(c)

Figure 6. The power for combined extrusion for un lubrication condition at friction factor
(c) 0.1
(b) 0.2
(c) 0.3

\section{Conclusion}

Combined backward forward extrusion process to produce hollow shapes was used to demonstrate the effect of friction factor and lubrication condition on temperature, load and power for workpiece of steel C45. FEM of 3D Q Form software is used to estimate the temperature distribution during the process, load values and power needed for this cold metal forming process . The study show when using lubricants the temperature of billet increases slowly with small differences when increase friction factor, while there is big increases in temperatures with increasing friction factor for un lubrication condition. For the load values, it was shown that it increases when friction factor increases and it was larger without lubrication than with lubrication conditions. The un lubrication affect the power significantly than un lubrication process and in both states the power increases with increase of friction factor. The non-uniform curves of load and power especially for un lubrication process related to the differences of contact area between work piece and the die ,when the contact area is full the change of the curves being linear but for not full contact area the curves change being not linear. The heat transfer between the die and work piece in the die has big influences on the curves, plastic strain affected the smoothness of load and power curves . 


\section{References}

[1] M O Mutlu , C G Guleryuz , Z Parlar 1. "Numerical investigation of the effect of friction conditions to increase die life "13th International Conference on Tribology, ROTRIB'16 IOP Publishing IOP Conf. Series: Materials Science and Engineering 174012046 doi:10 , 2017.

[2] A. Farhoumand , R.Ebrahimi "Analysis of forward- backward radial extrusion process " , AlSEVIER ,Materials and Design 30, 2152-2157, 2009.

[3] S.H kim , S.W. Chung, S. Padmanaban. " Investigation of lubrication effect on the backward extrusion of thin -walled rectangular aluminum case with large aspect ratio " Journal of materials processing Technology 185-192 180, 2006 .

[4] Shunpei Kamitani, Kenji Nakanishi, Yong-Ming Guo . " Performance evaluation of lubricant for producing smooth surface product in cold extrusion of aluminum using tool with micro groove arrays " $11^{\text {th }}$ international conference on tecknology of plasticity 19-24 Japan, 2014 .

[5] K.Kuzman , E. Pfeifer , N.Bay, J.Hunding . "Control of material flow in a combined backward can forward rod extrusion " Journal of Material Processing Technology 60 (141-147), 1996.

[6] Ryo Matsumoto, Kazunori Hayashi, Hiroshi Utsunomiya "Experimental and numerical analysis of friction in high aspect ratio combined forward - backward extrusion with retreat and advance pulse ram motion on a servo press " , ELSEVIER, Journal of Materials Processing Technology $214,936-944,2014$.

[7] Kanhu Charan Nayak, Susanta Kumar Sahoo . " Three dimensional analysis of combined extrusion -forging process ", Roll No. 211Me2352 ,National Institute of Technology Rourkela 769008, India, 2013.

[8] Moveh Samuel, Gambo Anthony. " Effects Of Vegetable Based Oils Lubricants In The Extrusion Of Aluminium" International journal of scientific and technology research volume 5, issue 08 , 2016 .

[9] H. Sönmez " Research of the effect of lubrication on extrusion load in direct extrusion " mechanical engineering, Turkey, 2016 .

[10] Armin Buschhausen, Klaus Weinmann, Joon Y. Lee, Taylan Altan . " Evaluation of lubrication and friction in cold forging using a double backward-extrusion process " Journal of Materials Processing Technology, 95-108 95 Elsevier 33, 1992.

[11] V.Jayaseelan , K .Kalaichelvan . " Influence of Friction Factor on Extrusion Process " Advanced Materials Research Vol 622-623 (2013) pp 457-460 Trans Tech Publications, Switzerland, 2013

[12] C. C. Chang, C. H. Hsu, J. C. Lai. " Estimation of friction factor at workpiece-die interface in combined forward and backward hollow extrusion of brass at micro scale " Texas A \& M International University, 2016 . 